\title{
Investigation on pyrolysis of some organic raw materials
}

\author{
B.Purevsuren*, Ya.Davaajav, S.Batbileg, A.Ariunaa, J.Namkhainorov, S.Jargalmaa, G.Tsatsral, \\ B.Bat-Ulzii, R.Erdenechimeg, M.Battsetseg, B.Avid, D.Batkhishig, J.Dugarjav \\ Institute of Chemistry and Chemical Technology, Mongolian Academy of Sciences, Peace Avenue, \\ Ulaanbaatar 13330, Mongolia
}

ARTICLE INFO: Received: 27 June, 2016; Revised: 02 Sep, 2016; Accepted: 05 Sep, 2016

\begin{abstract}
We have been working on pyrolysis of some organic raw materials including different rank coals, oil shale, wood waste, animal bone, cedar shell, polypropylene waste, milk casein and characterization of obtained hard residue, tar and pyrolytic water and gas after pyrolysis. The technical characteristics of these organic raw materials have been determined and the thermal stability characteristics such as thermal stability indices $\left(T_{5 \%}\right.$ and $\left.T_{25 \%}\right)$ determined by using thermogravimetric analysis. The pyrolysis experiments were performed at different heating temperatures and the yields of hard residue, tar, pyrolysis water and gaseous products were determined and discussed. The main technical characteristics of hard residue of organic raw materials after pyrolysis have been determined and the adsorption ability of pyrolysis hard residue and its activated carbon of organic raw materials also determined. The pyrolysis tars of organic raw materials were distilled in air condition and determined the yields of obtained light, middle and heavy fractions and bitumen like residue with different boiling temperature. This is the first time to investigate the curing ability of pyrolysis tars of organic raw materials for epoxy resin and the results of these experiments showed that only tar of milk casein has the highest (95.0\%), tar of animal bone has certain (18.70\%) and tars of all other organic raw materials have no curing ability for epoxy resin.
\end{abstract}

Keywords: Pyrolysis, hard residue, thermal indices, epoxy resin, curing agent, crosslinking reaction

Copyright $\odot 2016$ Purevsuren B, et al. This is an open access article distributed under the Creative Commons Attribution 4.0 International License CC BY, which permits unrestricted use, distribution, and reproduction in any medium, provided the original work is properly cited.

\section{INTRODUCTION}

Mongolia is a rich country with different kind natural organic raw materials including oil, coals, oil shale, wood and bioorganic materials of animal origin such as casein, animal bone and so on [1-3]. On the other hand pyrolysis is an efficient form (method) of treatment of organic material at elevated temperatures in the absence of oxygen. It involves the simultaneous change of chemical composition and physical phase during thermochemical decomposition of organic material by heat and is irreversible [4-6].

As a result of pyrolysis, solid (hard residue), condensed liquid (tar and pyrolysis water) and gas (uncondensed) products can be obtained. Solid product is porous material with higher caloric value which can be used as coke, semicoke, smokeless fuel, adsorbent material and so on. Tar is petroleum like product and can be used as complex raw material for production of chemical substances, gasoline, diesel, oils, bitumen and so on. The gas product can be used as gas fuel after cleaning of nitrogen and sulphur containing pollutants in it [4-5]. Generally before the pyrolysis experiments of organic raw materials have carried out thermogravimetric analysis of these materials to determine the thermal stability characteristics such as thermostability indices $\left(\mathrm{T}_{5 \%}\right.$ and $\left.\mathrm{T}_{25 \%}\right)$ and to evaluate how are easy for pyrolysis of them [7,8].

During last decade we are working on pyrolysis of some organic raw materials including different rank coals [9-10],

*corresponding author: e-mail: bpurevsuren.icct@gmail.com

DOI: http://dx.doi.org/10.5564/mjc.v17i43.739 oil shale [11-13], wood waste [14-16], animal bone [17, 18], cedar shell [19], polypropylene waste [20], milk casein [21-23] and characterization of obtained hard residue, tar and gas product after pyrolysis. We have investigated different kind coals of more than 20 deposits and have selected results of only 3 coals including Nariin sukhait (as a high rank coal), Bayanteeg (as a middle rank coal) and Dornod Khoot (as a low rank coal) coal in this paper. Also these coals locate in different parts of Mongolian territory for example Nariin sukhait coal deposit is in the south, Bayanteeg coal deposit in the west and Dornod Khoot coal deposit in the eastern part of Mongolia. Also we have investigated oil shales of more than 10 deposits and here was selected only oil shale of Khoot deposit as the most investigated one.

There are a lot of waste materials from wood, cedar shell bone, animal bone and plastics, which are not exploiting and polluting the environment in Mongolia. Therefore have been selected these waste materials for pyrolysis processing as a method for utilization of them. The milk casein was selected as a pure bioorganic material and the pyrolysis hard residue and tar were much different than those of all other selected organic raw materials.

The pyrolysis experiments of these selected organic raw materials have been carried out by using a small scale quarts retort at different heating temperatures (200-700 ${ }^{\circ} \mathrm{C}$ ) and determined the yields of solid, liquid and gas products and selected an optimum temperature in which the yield of tar is higher for each organic raw material. For more quantity of tar have used a bigger scale retort 
designed by us and the collected tars purified from the pyrolysis water. So collected and purified tar a subject for atmospheric distillation to obtain fractions with different boiling temperature ranges. It is necessary to emphasize that the pyrolysis of animal bone, casein and cedar shell was investigated first time by us and obtained hard residues with porosity structure and tars with different chemical composition than that of tars from coal, oil shale and wood. Also first time have been investigated the curing ability of pyrolysis tars of organic raw materials for epoxy resin.

\section{EXPERIMENTAL}

The samples of organic raw materials were crushed into pieces of 3-6 $\mathrm{mm}$ size and the analytical sample was prepared by powdering to a particle size $<0.2 \mathrm{~mm}$ in a vibration steel mill. Analytical sample preparation (MNS 2719 : 2001), proximate and ultimate analysis of of organic raw materials were performed according to Mongolian National Standards MNS 656-79 (moisture content), MNS 652-79 (ash yield), MNS 654-79 (volatile matter yield).

Thermogravimetric analysis initial organic raw materials carried out in DTA/TG7200, Hitachi, Japan model equipment. Conditions of analysis were: Sample weight $5-10 \mathrm{mg}$, Heating temperature range $20-1150^{\circ} \mathrm{C}$, Heating rate $40^{\circ} \mathrm{C} / \mathrm{min}$, Carrier gas-nitrogen, Crucible-Pt.

The pyrolysis experiments were performed at different heating temperatures in a laboratory small scale quartz retort (tube) loaded with $1 \mathrm{~g}$ of powdered organic raw materials (with particle sizes of $<0.2 \mathrm{~mm}$ ). The retort was placed in a horizontal electric tube furnace with a maximum heating temperature of $950^{\circ} \mathrm{C}$. A chromealumel thermocouple was immersed in the tube furnace to measure the actual heating temperature. The pyrolysis experiments were performed at different heating temperatures $200-700^{\circ} \mathrm{C}$ with constant heating rate $20^{\circ} \mathrm{C} /$ min. First of all the quartz retort with casein sample was heated for example to $600^{\circ} \mathrm{C}$ with heating rate $20^{\circ} \mathrm{C} / \mathrm{min}$. and kept at $700^{\circ} \mathrm{C}$ for $80 \mathrm{~min}$. The retort was connected with a thermostable glass tube heated also in a tube furnace at $80^{\circ} \mathrm{C}$ for collecting of tars and this tube is also connected with a air-cooled glass vessel for collecting of pyrolysis water. The glass vessel for pyrolysis water is also connected with a thin glass tube for non-condensable gases. The yields of pyrolysis products including solid residue (biochar), tar (condensed liquid product) and pyrolysis water determined by weighing, and the yield of gases by differences.

The preparative-scale pyrolysis experiments of organic raw materials samples were performed in a laboratory vertical cylindrical retort made by stainless steel which could contain $1000 \mathrm{~g}$ of sample. The retort was placed in an electric furnace (model SNOL) with a maximum temperature of $950^{\circ} \mathrm{C}$. A chrome-alumel thermocouple was immersed in the sample bed to measure the actual heating temperature and an equipment for temperature control (potentiometer). The retort was connected with an air-cooled iron tube and water-cooled laboratory glass condenser and a collection vessel for the condensate of liquid product (pitch and pyrolysis water). The noncondensable gases after water-cooled condenser were left the system through a thin glass tube. The experiments were carried out to $900^{\circ} \mathrm{C}$ temperature and the heating rate was $20^{\circ} \mathrm{C} / \mathrm{min}$. The yields of products including solid residue (char), tar and pyrolysis water determined by weighing, and the yield of gases by difference.

Method for separation of tar and pyrolysis water: The liquid condensed by-product of organic raw materials pyrolysis consists from tar and pyrolysis water. They form an unmixed two layers and can be separated easily by separating glass funnel. The upper layer is tar (viscous liquid) with black-brown color and unpleasant smell. The bottom layer is pyrolysis water (non viscous liquid) with bad smell and brown color. The final cleaning of tar from the pyrolysis water residue usually use thermally treated $\mathrm{CaCl}_{2}$ by mixing and separating (filtering or centrifuging). Atmospheric distillation of tar was performed in a laboratory glass unit and the yields of fractions (light, middle, heavy and residue) with different boiling temperature range were obtained.

Method for curing of epoxy resin with tar: A sample of $1.0 \mathrm{~g}$ epoxide resin of ED mark is mixing with $15-20 \%$ tar in small glass vessel and form a homogenous mixture. No curing of epoxide resin mixture occurred under ambient temperature for $24 \mathrm{~h}$. Therefore the mixture was put in an oven at $120^{\circ} \mathrm{C}$ for $2 \mathrm{~h}$ where curing of epoxy resin took place and hard glass-like product was formed. The cured epoxide resin was powdered in a vibration steel mill and $1.0 \mathrm{~g}$ of sample was loaded into a previously weighed filter paper and then extracted with acetone in a Sohxlet apparatus. After finishing of extraction the sample in filter paper have to dry at $105^{\circ} \mathrm{C}$ in oven until constant weight and than will be determined the insoluble in acetone fraction (gel fraction or degree of curing reaction of epoxy resin, \%). The pyrolized coal samples (10-15 g) have been replaced in quarts tube and flowed with nitrogen to remove the oxygen and heated until $800^{\circ} \mathrm{C}$ and processed (activated) with heated water steam for 120 minutes.

The iodine number, $\%$ is defined as the number of milligrams of iodine adsorbed from an agueous solution by $1 \mathrm{~g}$ of activated carbon when the iodine concentration of the residual filtrate is $0.02 \mathrm{~N}$.

Granular activated carbon is pulverized $(<0.1 \mathrm{~mm})$ and then dried at $150^{\circ} \mathrm{C}$ to constant weight. Depending on the activity of the activated carbon, $1 \mathrm{~g}$ weigh of dried carbon, and transfered the weighed sample to a dry, glass stoppered $250 \mathrm{ml}$ flask then added by pipette $50 \mathrm{ml}$ of $0.10 \mathrm{~N}$ iodine solution. Stopper the flask immediately and shaked it vigorously for 30 seconds. Filtered by gravity through a filter paper immediately after the 30 seconds shaking period. Stirred the filtrate in the breaker with a glass rod and pipette $50 \mathrm{ml}$ into a $250 \mathrm{ml}$ flask. Titrated the $50 \mathrm{ml}$ sample with $0.10 \mathrm{~N}$ sodium thiosulphate solution until the yellow colour has almost disappeared. Added about $1 \mathrm{ml}$ of starch solution and continued titration until the blue indicator colour just disappeared. Recorded the volume of sodium thiosulphate solution used.

To calculate the iodine number $(X)$ of the carbon below equation was used:

Where:

$$
\mathrm{X} \%=\frac{\left(\mathrm{V}_{0}-\mathrm{V}_{1}\right) * 0.0127 * 100 * 50}{\mathrm{~m} * 10}
$$

$\mathrm{V}_{1}$ - volume of sodium thiosulphate solution, $\mathrm{ml}$

$\mathrm{m}$ - mass of activated carbon, $\mathrm{g}$

50 - iodine solution of $0.10 \mathrm{~N}$ added into weighed sample $\mathrm{ml}$ 
The methylene blue adsorption value, $\mathrm{mg} / \mathrm{g}$ is defined as the number of millilitres standart methylene blue solution decolourized by $0.1 \mathrm{~g}$ of activated carbon (dry basis). Granular activated carbon is pulverized $(<0.1 \mathrm{~mm})$ and then dried at $150^{\circ} \mathrm{C}$ to constant weight. Contacted exactly $0.1 \mathrm{~g}$ of the carbon sample with $25(5) \mathrm{ml}$ of the methylene blue test solution in a glass stoppered flask. Shaked until decolourization occurs. Then added a 5(1) $\mathrm{ml}$ of the methylene blue test solution and shaked until decolourization. Repeated the addition of methylene blue test solution in 5(1) $\mathrm{ml}$ portions as long as decolourization occured within five minutes. The entire volume of test solution decolourized by the sample. Repeated the test to confirm the result obtained. The volume of methylene blue test solution in $\mathrm{ml}$ that is just decolourized, was the methylene blue value of the activated carbon.

\section{RESULTS AND DISCUSSION}

First of all the thermal stability of initial organic raw materials was studied by thermogravimetric analysis and determined the thermal stability indices from the TG curve of each organic raw material. The determined thermal stability indices are given in Table 1.

Table 1. Thermal stability indices of organic raw materials

\begin{tabular}{lcc}
\hline \multirow{2}{*}{ Organic raw materials } & \multicolumn{2}{c}{$\begin{array}{c}\text { Thermal stability } \\
\text { indices, }{ }^{\circ} \mathbf{C}\end{array}$} \\
\cline { 2 - 3 } & $\mathbf{T}_{5 \%}$ & $\mathbf{T}_{25 \%}$ \\
\hline Nariin sukhait coal (high rank) & 447.37 & 738.73 \\
Bayanteeg coal (middle rank) & 359.00 & 542.42 \\
Dornod Khoot coal (low rank) & 128.98 & 537.70 \\
Khoot oil shale & 445.26 & - \\
Wood waste & 84.180 & 311.19 \\
Animal bone & 161.45 & 444.34 \\
Cedar shell bone & 72.490 & 295.39 \\
Casein & 101.93 & 299.51 \\
Polypropylene waste & 403.61 & 436.51 \\
\hline
\end{tabular}

The thermal stability indices of organic raw materials in Table 1 show that the coal of Nariin sukhait deposit and oil shale of Khoot deposit have the highest thermal stability than that of all other organic raw materials. As it seen that 3 coal samples have much different thermal stability indices, because the coal of Nariin sukhait is classified as a high rank hard bituminous coal with coking property. The thermal stability indices of Bayanteeg coal are less than Nariin sukhait coal and higher than Dornod Khoot coal, because this is a middle rank subbituminous coal with poor coking property. The thermal stability indices of Dornod Khoot coal are lowest than Nariin sukhait and Bayanteeg coals, because this is a low rank brown coal of lignite type with non coking property. All natural bioorganic raw materials including wood waste, cedar shell bone, animal bone and casein characterize with much lower thermal stability indices than that of coal and oil shale. It is interesting that the synthetic organic polymer polypropylene hasmuch higher thermal stability indices than that of natural bioorganic raw materials and slightly less than that of coal. much higher thermal stability indices than that of natural bioorganic raw materials and slightly less than that of coal. The groups of oil shale from solid fuel and animal bone from bioorganic materials are characterize with much higher content of ash (Table 2) and therefore they also have higher thermal stability indices than that of each group.

Main technical characteristics of organic raw materials have been determined by standard methods and are given in Table 2.

All analytical samples of organic raw materials have lower content of moisture and it is higher in the case of Dornod Khoot coal, cedar shell bone and casein. The ash content in organic raw materials is much different. As mentioned above the oil shale and animal bone have the highest ash content than that of all other organic raw materials. As pure bioorganic materials such as wood, casein, cedar shell bone and also synthetic polypropylene have the lowest ash content. In the case of different rank coals they have higher ash content than that of bioorganic materials. The volatile matters content is very important characteristic for the degree of conversion or thermal stability of the organic raw materials during thermal decomposition. According to this pure organic materials including wood, casein, cedar shell bone, polypropylene and also oil shale have much higher volatile matter content than that of coals. This is an indication that the coal organic mass is characterized with much higher thermal stability than that of other organic materials. Also coals characterize with much higher caloric value than that of other organic materials. After characterization and determination of thermal stability of organic raw materials the small-

Table 2. Technical characteristics of organic raw materials

\begin{tabular}{|c|c|c|c|c|}
\hline \multirow[b]{2}{*}{ Organic raw materials } & \multicolumn{4}{|c|}{ Technical characteristics } \\
\hline & Moisture, $\mathbf{W}^{\mathrm{a}, \%}$ & Ash, $A^{d}, \%$ & Volatile matters, $V^{\text {daf }}, \%$ & $\begin{array}{c}\text { Calorific value, } \\
\mathbf{Q}^{\text {daf }}, \mathrm{\kappa cal} / \mathrm{kg}\end{array}$ \\
\hline Nariin sukhait coal (high rank) & 1.00 & 15.80 & 36.90 & 7685.00 \\
\hline Bayanteeg coal (middle rank) & 3.34 & 12.17 & 47.61 & 7310.95 \\
\hline Dornod Khoot coal (low rank) & 11.04 & 8.90 & 46.78 & 6232.79 \\
\hline Khoot oil shale & 2.09 & 78.45 & 94.82 & 919.540 \\
\hline Wood waste & 5.20 & 0.60 & 90.30 & 5623.16 \\
\hline Animal bone & 5.68 & 67.17 & 86.06 & 3604.00 \\
\hline Cedar shell bone & 10.49 & 0.61 & 87.37 & 4912.00 \\
\hline Casein & 7.72 & 5.95 & 78.01 & 5499.91 \\
\hline Polypropylene waste & 1.40 & 4.20 & 62.80 & - \\
\hline
\end{tabular}


Table 3. The yields of pyrolysis products of organic raw materials at different heating temperatures

\begin{tabular}{|c|c|c|c|c|c|}
\hline \multirow{2}{*}{$\begin{array}{l}\text { Organic raw } \\
\text { materials }\end{array}$} & \multirow{2}{*}{$\begin{array}{c}\text { Heating } \\
\text { temperatures, }{ }^{\circ} \mathrm{C}\end{array}$} & \multicolumn{4}{|c|}{ The yield of pyrolysis products, $\%$} \\
\hline & & Hard residue & Tar & Pyrolytic water & Gas \\
\hline \multirow{6}{*}{$\begin{array}{l}\text { Nariin sukhait coal } \\
\text { (high rank) }\end{array}$} & 200 & 99.25 & - & 0.25 & 0.50 \\
\hline & 300 & 97.86 & 0.30 & 1.09 & 0.75 \\
\hline & 400 & 95.32 & 0.73 & 2.47 & 1.48 \\
\hline & 500 & 92.98 & 1.05 & 3.50 & 2.47 \\
\hline & 600 & 88.53 & 2.40 & 4.00 & 5.07 \\
\hline & 700 & 83.79 & 3.66 & 6.50 & 6.05 \\
\hline \multirow{6}{*}{$\begin{array}{l}\text { Bayanteeg coal } \\
\text { (middle rank) }\end{array}$} & 200 & 95.72 & 0.10 & 0.16 & 4.02 \\
\hline & 300 & 94.07 & 1.71 & 0.29 & 3.93 \\
\hline & 400 & 69.72 & 12.03 & 4.27 & 13.98 \\
\hline & 500 & 66.75 & 14.57 & 5.46 & 13.22 \\
\hline & 600 & 63.86 & 13.16 & 3.41 & 19.57 \\
\hline & 700 & 61.85 & 10.17 & 2.08 & 25.9 \\
\hline \multirow{6}{*}{$\begin{array}{l}\text { Dornod Khoot coal } \\
\text { (low rank) }\end{array}$} & 200 & 84.39 & 0.38 & 6.15 & 9.08 \\
\hline & 300 & 80.75 & 0.40 & 8.83 & 10.02 \\
\hline & 400 & 57.68 & 9.92 & 14.24 & 18.16 \\
\hline & 500 & 57.11 & 9.42 & 13.98 & 19.49 \\
\hline & 600 & 48.74 & 6.33 & 12.47 & 32.46 \\
\hline & 700 & 45.90 & 4.23 & 11.94 & 37.93 \\
\hline \multirow{6}{*}{ Khoot oil shale } & 200 & 98.69 & - & 0.94 & 0.36 \\
\hline & 300 & 97.25 & 0.51 & 0.62 & 1.61 \\
\hline & 400 & 96.17 & 0.91 & 2.11 & 0.79 \\
\hline & 500 & 90.57 & 2.55 & 2.50 & 1.32 \\
\hline & 600 & 89.99 & 3.93 & 0.72 & 5.35 \\
\hline & 650 & 86.85 & 4.07 & 1.62 & 7.44 \\
\hline \multirow{6}{*}{ Wood waste } & 200 & - & - & - & - \\
\hline & 300 & 37.74 & 16.28 & 22.28 & 23.70 \\
\hline & 400 & 27.30 & 20.55 & 28.10 & 23.03 \\
\hline & 500 & 27.50 & 21.40 & 29.40 & 21.70 \\
\hline & 600 & 27.90 & 21.46 & 29.43 & 21.21 \\
\hline & 700 & 25.45 & 21.58 & 29.50 & 23.52 \\
\hline \multirow{6}{*}{ Animal bone } & 200 & 93.20 & 1.30 & 2.98 & 2.52 \\
\hline & 300 & 83.02 & 2.63 & 7.53 & 6.82 \\
\hline & 400 & 75.12 & 4.84 & 13.10 & 6.94 \\
\hline & 500 & 70.86 & 6.55 & 13.27 & 9.32 \\
\hline & 600 & 69.71 & 7.21 & 12.57 & 10.51 \\
\hline & 700 & 68.60 & 7.30 & 12.10 & 12.00 \\
\hline \multirow{7}{*}{ Cedar shell bone } & 200 & 93 & 0.56 & 1.68 & 4.76 \\
\hline & 300 & 42.85 & 4.66 & 14.01 & 38.48 \\
\hline & 400 & 33.35 & 7.71 & 23.16 & 35.78 \\
\hline & 500 & 29.98 & 13.09 & 33.29 & 23.64 \\
\hline & 600 & 26.75 & 10.32 & 30.98 & 31.95 \\
\hline & 700 & 26.57 & 8.16 & 24.49 & 40.78 \\
\hline & 800 & 23.54 & 6.90 & 20.73 & 48.83 \\
\hline \multirow{6}{*}{ Casein } & 200 & 86.44 & 0.62 & 0.67 & 11.68 \\
\hline & 300 & 59.71 & 8.76 & 4.97 & 26.35 \\
\hline & 400 & 57.30 & 10.24 & 5.79 & 26.47 \\
\hline & 500 & 23.78 & 31.60 & 17.56 & 26.97 \\
\hline & 600 & 21.14 & 36.85 & 20.57 & 21.17 \\
\hline & 700 & 20.61 & 36.22 & 20.06 & 23.11 \\
\hline Polypropylene waste & 700 & 1.00 & 83.50 & - & 15.50 \\
\hline
\end{tabular}


scale pyrolysis experiments were performed in a laboratory quartz retort (tube) at different heating temperatures and have been determined the yields of obtained hard residue, tar, pyrolytic water and gas (Table 3).

This is an indication that the coal organic mass is characterized with much higher thermal stability than that of other organic materials. Also coals characterize with much higher caloric value than that of other organic materials. After characterization and determination of thermal stability of organic raw materials the small-scale pyrolysis experiments were performed in a laboratory quartz retort (tube) at different heating temperatures and have been determined the yields of obtained hard residue, tar, pyrolytic water and gas (Table 3). These results show that the yield of tar, pyrolysis water and gas increased with rising the temperature of pyrolysis. Only the yield of hard residue was decreased at the same time. The formed tar and hard residue were the most important products for us. Certain yield of tar is lower at lower temperature, because the thermal decomposition was not enough. The optimum temperature for pyrolysis of each organic raw material is different according to the yield of tar. For example the highest yield (83.5\%) of tar obtained at heating temperature $700^{\circ} \mathrm{C}$ during pyrolysis of synthetic polypropylene, for pure biopolymer casein was selected $600^{\circ} \mathrm{C}$, in which the yield of tar is higher-36.85\%. The yield of tar is lowest- $3.6 \%$ in the case of high rank coal Nariin sukhait at $700^{\circ} \mathrm{C}$ and $4.0 \%$ for Khoot oil shale at $650^{\circ} \mathrm{C}$. In the case of coals from Bayanteeg and Dornod Khoot, wood waste, animal bone and cedar shell bone the yield of tar is in the middle position from 7.30 to $21.50 \%$ at the heating temperature range $600-700^{\circ} \mathrm{C}$. In the case of synthetic polypropylene almost not remained hard residue and no formed pyrolysis water during the pyrolysis as it was expected theoretically, there are no hydroxyl and other oxygen containing functional groups in the macromolecules of polypropylene. After determination of optimal heating temperatures of pyrolysis of each organic raw material in which the yield of tar is higher have been collected larger amount of hard residue and tar by pyrolysis in bigger scale retort designed by us. The collected amount of tar and pyrolysis water then separated by the method described in experimental part and for example $100 \mathrm{ml}$ pure tar of each organic raw material was obtained for the next analysis. Main technical characteristics of hard residue after pyrolysis of organic raw materials have been determined and are given in Table 4.

The data in Table 4 show that the content of moisture and volatile matter decreased while the content of ash and calorific value were increasing after pyrolysis.

Table 4. Technical characteristics of hard residues after pyrolysis of organic raw materials

\begin{tabular}{|c|c|c|c|c|}
\hline \multirow[b]{2}{*}{ Organic raw materials } & \multicolumn{4}{|c|}{ Technical characteristics } \\
\hline & Moisture, $\mathbf{W}^{\mathrm{a}}, \%$ & Ash, $A^{d}, \%$ & $\begin{array}{c}\text { Volatile } \\
\text { matters, } \mathbf{V}^{\text {daf }}, \%\end{array}$ & $\begin{array}{c}\text { Calorific value, } \\
\mathbf{Q}^{\text {daf }}, \text { ксаl/кg }\end{array}$ \\
\hline Nariin sukhait coal (high rank) & 2.50 & 11.50 & 2.80 & 8156.00 \\
\hline Bayanteeg coal (middle rank) & 0.72 & 16.23 & 9.47 & 8039.92 \\
\hline Dornod Khoot coal (low rank) & 0.84 & 12.80 & 8.79 & 7884.18 \\
\hline Khoot oil shale & - & - & - & - \\
\hline Wood waste & 0.56 & 1,60 & 4.60 & 8165.00 \\
\hline Animal bone & 2.80 & 87.30 & 9.05 & 560.330 \\
\hline Cedar shell bone & 0.79 & 5.73 & 17.29 & 8738.00 \\
\hline Casein & 4.12 & 20.46 & 18.75 & 6997.84 \\
\hline Polypropylene waste & - & - & - & - \\
\hline
\end{tabular}

Table 5. Adsorption ability of pyrolysis hard residue and it's activated carbon of organic raw materials

\begin{tabular}{llc}
\hline Organic raw materials & lodine adsorption, \% & Methylene blue adsorption, $\mathbf{m g} / \mathbf{g}$ \\
\hline Nariin sukhait coal (hard residue) & 1.30 & 29.40 \\
Nariin sukhait coal (activated hard residue) & 27.20 & 57.90 \\
Bayanteeg coal (hard residue) & 4.28 & 1.20 \\
Bayanteeg coal (activated hard residue) & 26.35 & 6.00 \\
Dornod Khoot coal (hard residue) & 7.50 & 30.00 \\
Dornod Khoot coal (activated hard residue) & 23.80 & 126.70 \\
Casein (hard residue) & 5.39 & 3.60 \\
Casein ( activated hard residue) & 19.32 & 13.19 \\
Animal bone (hard residue) & 8.23 & 37.17 \\
Animal bone (activated hard residue) & 8.55 & 36.98 \\
Cedar slell (hard residue) & 6.65 & 21.56 \\
Cedar shell (activated hard residue) & 38.62 & 75.53 \\
Wood waste (hard residue) & 5.39 & 14.38 \\
Wood waste (activated hard residue) & 39.89 & 100.6 \\
\hline
\end{tabular}


Table 6 . The yield of fractions of tars with different boiling temperature range

\begin{tabular}{|c|c|c|c|}
\hline Organic raw materials & Boiling temperature range, ${ }^{\circ} \mathrm{C}$ & Yield of fraction, $\%$ & Appearance \\
\hline \multirow{8}{*}{ Nariin sukhait coal (high rank) } & untill 180 & 1.70 & Light (liquid) \\
\hline & $180-230$ & 2.00 & Middle (liquid) \\
\hline & $230-250$ & 4.20 & Middle (liquid) \\
\hline & $250-280$ & 5.00 & Middle (liquid) \\
\hline & $280-320$ & 7.10 & Heavy (liquid) \\
\hline & $320<$ & 6.50 & Heavy (liquid) \\
\hline & Solid residue & 73.50 & Solid \\
\hline & Gas and loss & 0.00 & Gas \\
\hline \multirow{7}{*}{ Bayanteeg coal (middle rank) } & Until 180 & 11.58 & Light (liquid) \\
\hline & $180-230$ & 13.24 & Middle (liquid) \\
\hline & $230-250$ & 5.84 & Middle (liquid) \\
\hline & $250-280$ & 8.79 & Middle (liquid) \\
\hline & $280-320$ & 7.67 & Heavy (liquid) \\
\hline & $320<$ & 51.02 & Solid \\
\hline & Gas and loss & 1.86 & Gas \\
\hline \multirow{7}{*}{ Dornod Khoot coal (low rank) } & untill 180 & 45.36 & Light (liquid) \\
\hline & $180-230$ & 9.22 & Middle (liquid) \\
\hline & $230-250$ & 3.60 & Middle (liquid) \\
\hline & $250-280$ & 3.90 & Middle (liquid) \\
\hline & $280-320$ & 13.66 & Heavy (liquid) \\
\hline & $320<$ & 20.34 & Solid \\
\hline & Gas and loss & 3.92 & Gas \\
\hline \multirow{5}{*}{ Khoot oil shale } & Untill 180 & 14.20 & Light (liquid) \\
\hline & $180-280$ & 28.40 & Middle (liquid) \\
\hline & $280-320$ & 4.90 & Heavy (liquid) \\
\hline & $320<$ & 36.80 & Solid \\
\hline & Gas and loss & 15.70 & Gas \\
\hline \multirow{5}{*}{ Wood waste } & Until 150 & 31.70 & Light (liquid) \\
\hline & $150-200$ & 7.10 & Middle (liquid) \\
\hline & $200-250$ & 20.10 & Heavy (liquid) \\
\hline & $250<$ & 37.50 & Solid \\
\hline & Gas and loss & 3.60 & Gas \\
\hline \multirow{5}{*}{ Animal bone } & Until 210 & 29.00 & Light (liquid) \\
\hline & $210-320$ & 27.56 & Middle (liquid) \\
\hline & $320-380$ & 7.23 & Heavy (liquid) \\
\hline & $380<$ & 27.73 & Solid \\
\hline & Gas and loss & 8.48 & Gas \\
\hline \multirow{4}{*}{ Cedar shell bone } & Until 180 & 10.38 & Light (liquid) \\
\hline & $180-250$ & 32.99 & Middle (liquid) \\
\hline & $250-280$ & 21.32 & Heavy (liquid ) \\
\hline & $280<$ & 35.39 & Solid \\
\hline \multirow{6}{*}{ Casein } & Until 150 & 10.50 & Light (liquid) \\
\hline & $150-200$ & 22.70 & Light (liquid) \\
\hline & $200-250$ & 34.00 & Middle (liquid) \\
\hline & $250-300$ & 5.70 & Heavy (liquid) \\
\hline & $300<$ & 17.70 & Solid \\
\hline & Gas and loss & 9.40 & Gas \\
\hline \multirow{7}{*}{ Polypropylene waste } & $30-100$ & 14.60 & Light (liquid) \\
\hline & $100-150$ & 32.70 & Light (liquid) \\
\hline & $150-200$ & 17.03 & Light (liquid) \\
\hline & $200-300$ & 15.06 & Middle (liquid) \\
\hline & $300-350$ & 12.00 & Middle (liquid) \\
\hline & $350<$ & 8.70 & Heavy (liquid) \\
\hline & Gas and loss & - & - \\
\hline
\end{tabular}


The decreased content of volatile matter shows that there was intensive thermal decomposition of each organic raw material during the pyrolysis. The pyrolysis hard residue is also important product of pyrolysis of each organic raw material and it is characterizing with certain porosity structure. To increase the porosity of pyrolysis hard residue, the preheated water steam has been used as an activation agent flowing the preheated water steam through the bed of pyrolysis hard residue for $180 \mathrm{~min}$. Therefore the adsorption ability of pyrolysis hard residue and it's activated carbon of organic raw materials have been determined and the results are given in Table 5 .

The data in Table 5 show that the adsorption ability (iodine and methylene blue adsorption) of activated carbon from pyrolysishard residue ofeachorganicrawmaterialincreased drastically (several times) than that of initial pyrolysis hard residue. The iodine adsorption is a characteristic of pores with methylene blue adsorption is a characteristic of pores with bigger sizes.

For the next investigation on characterization of tar have been used an atmospheric distillation of purified tar and obtained light, middle, heavy fractions and distillation residue with different boiling temperatures and the yield of these fractions are given in Table 6.

All pyrolysis tars from different organic raw materials are similarly characterizing viscous liquid with very bad smell and black brown color. The different number of light and middle fractions for instance, 3 light fractions from polypropylene tar, 2 from casein tar, 3 middle fractions from all coal tars, and 2 from polypropylene tar were obtained depending on the consistence of each tar. Have obtained 1 light, middle and heavy fraction from each oil shale, animal bone, cedar shell bone and wood waste tars. Also the yield fractions of each tar were different depending their consistence. For example the yield of fractions was very low whereas the yield of distillation residue is high in the case of coal tars. The yield of fractions are high in all tars from other organic raw materials whereas the yield of distillation residues are low. The highest yields of light fractions were obtained from polypropylene and casein tars. The color of each fractions was also different shown as yellow for all light fractions, brown for all middle fractions, black brown for all heavy fractions and black for distillation residue. We call light fractions-gasoline, middle fractions-diesel, heavy fractions-kerosene, and distillation residue-bitumen fractions. To use these fractions as gasoline, diesel, kerosene and bitumen it is necessary to remove toxic organic acids, organic bases and phenolic compounds.

The investigation on a specific application of tars of all organic raw materials as curing agent for epoxy resin has been carried out. Epoxy resins known as polyepoxides are class of reactive prepolymers which contain epoxide groups. The epoxide groups of epoxy resins may be reacted (cross-linked) with a wide range of co-reactants (curing agents) with reactive $\mathrm{H}$ atoms in the functional groups including polyfunctional amines, acids (and acid anhydrides), phenols, alcohols, and tiols [15]. The results of testing pyrolysis tar from different organic raw materials as a curing agent for epoxy resin are given in Table 7 . Our preliminary tests showed that casein and animal bone tars had a certain property of curing agent for epoxy resin.
Therefore it is expected that the content of nitrogen in tars is important characteristic for curing reaction of epoxy resin (Table 7).

Table 7. The results of testing pyrolysis tar from different organic raw materials as a curing agent for epoxy resin

\begin{tabular}{lcc}
\hline $\begin{array}{c}\text { Pyrolysis tar from } \\
\text { different organic } \\
\text { raw materials }\end{array}$ & $\begin{array}{c}\text { Nitrogen } \\
\text { content of } \\
\text { tars, \% }\end{array}$ & $\begin{array}{c}\text { Curing ability of } \\
\text { Epoxy resin with } \\
\text { tar from different } \\
\text { organic raw } \\
\text { materials, \% }\end{array}$ \\
\hline $\begin{array}{l}\text { Nariin sukhait coal } \\
\text { (high rank) tar }\end{array}$ & $<2.0$ & no \\
$\begin{array}{l}\text { Bayanteeg coal } \\
\text { (middle rank) tar }\end{array}$ & $<2.0$ & no \\
Dornod Khoot coal & $<2.0$ & no \\
(low rank) tar & $<2.0$ & no \\
Oil shale tar & $<2.0$ & no \\
Wood waste tar & 0.00 & no \\
Polypropylene tar & $<2.0$ & no \\
Cedar shell tar & 7.60 & 18.78 \\
Bone tar & 12.1 & 95.00 \\
Casein tar & &
\end{tabular}

As mentioned above the casein pyrolysis tar differs from the tar of coal, oil shale and wood with it's higher content of organic bases and thickening properties during storage time. These thickening properties indicate that there are substances sensitive to oxidation and polymerization. This property and chemical composition of tar by $\mathrm{GC} /$ MS analysis were an evidence for using it as a curing agent for crosslinking reactions of epoxy resins [23]. The necessary amount of tar for curing reaction of epoxy resin was determined experimentally as a $15-20 \%$ for the stoichiometric amount of epoxy resin with $15-20 \%$ epoxy group content. The tar has good compatibility with epoxy resin and the sample was cured at $120^{\circ} \mathrm{C}$ for 2 hour in oven. It is known that most epoxy resins have excellent solubility in acetone, but after the curing reaction with tar the sample was turning to a solid material that is insoluble in acetone, more than $95 \%$ (the degree of curing reaction). Therefore the casein pyrolysis tar can be used successfully as a good curing agent for epoxy resin, because we have achieved the same degree of curing reaction with diethylenetriamine and maleic anhydride, which are the commercial curing agents for epoxy resins. The content of nitrogen in tars is much different depending on their origin. As a bioorganic material the casein tar has the highest content of nitrogen. In the case of bone tar the content of nitrogen is lower than in casein tar. The tars of coal, oil shale and wood waste have the lowest content of nitrogen, because their origin is different than casein and bone.

The results of these experiments showed that only tar of milk casein has the highest (95.0\%), tar of animal bone has certain (18.70\%) and tars of all other organic raw materials have no curing ability for epoxy resin. The curing ability of tars from different organic raw materials depends on the nitrogen content ( $\mathrm{N}$-containing functional groups intar) of tars. For example the tar of casein has the highest content of nitrogen $(12.1 \%)$, the tar of animal bone has middle content of nitrogen $(12.1 \%)$ and tars of all other organic raw materials 
have the lowest content of nitrogen (<2.0\%) [24, 25]. Epoxy resins known as polyepoxides are class of reactive prepolymers which contain epoxide groups. The epoxide groups of epoxy resins may be reacted (cross-linked) with a wide range of co-reactants (curing agents) with reactive $\mathrm{H}$ atoms in the functional groups including polyfunctional amines, acids (and acid anhydrides), phenols, alcohols, and tiols.

\section{CONCLUSION}

1. The technical characteristics of selected organic raw materials including different rank coals, oil shale, wood waste, animal bone, cedar shell, polypropylene waste, milk casein have been determined and the thermal stability characteristics such as thermal stability indices $\left(\mathrm{T}_{5 \%}\right.$ and $\left.\mathrm{T}_{25 \%}\right)$ determined and evaluated by using thermogravimetric analysis.

2. The pyrolysis experiments of organic raw materials at different heating temperatures performed in a laboratory small scale quartz retort and determined the yields of hard residue, tar, pyrolysis water and gas. These yields of pyrolysis product of different organic raw materials at different heating temperatures are explained and compared.

3. Main technical characteristics of hard residue of organic raw materials after pyrolysis have been determined and the adsorption ability (iodine and methylene blue adsorption) of pyrolysis hard residue and it's activated carbon of organic raw materials were determined as well. These results show that the activated chars of pyrolysis hard residues can have applications for purification of aste water and polluted gases.

4. The pyrolysis tars of organic raw materials isolated from pyrolysis water were distilled in air condition and determined the yields of obtained light, middle, heavy fractions and bitumen like residue with different boiling temperature.

5. The curing ability of pyrolysis tars of organic raw materials for epoxy resin have been investigated for the first time. The results of these experiments showed that only tar of milk casein has the highest $(95.0 \%)$, tar of animal bone has certain $(18.70 \%)$ and tars of all other organic raw materials have no curing ability for epoxy resin. The curing ability of tars from different organic raw materials depends on the nitrogen content ( $\mathrm{N}$-containing functional groups in tar) of tars. For example the tar of casein has the highest content of nitrogen $(12.1 \%)$, the tar of animal bone has middle content of nitrogen $(7.6 \%)$ and tars of all other organic raw materials have the lowest content of nitrogen $(<20 \%)$.

\section{REFERENCES}

1. B.Purevsuren, Ya.Davaajav, R.Erdenechimeg. (2010) Investigation on coals from some Mongolian deposits. Toonotprint publisher, Ulaanbaatar, 14-22 (in Mongolian).

2. B.Avid, B.Purevsuren, J.Temuujin. (2016) Bituminous Coals of Mongolia: Occurrence and Characteristics. In: Advances in Energy Research Morena J.Acosta (ed.), 22. Chapter 7, Nova Publishers, New York, 159-178.
3. B.Avid, Y.Sato, K.Maruyama,Y.Yamada, B.Purevsuren. (2004) Effective utilization of Mongolian coal by upgradinginasolvent. FuelProcess. Tech., 85, 933-945.

4. B.Purevsuren, Ya.Davaajav. (2006) Investigation on pyrolysis of some organic raw materials, Toonotprint publisher, Ulaanbaatar, 11-28 (in Mongolian).

5. B.Purevsuren. (2003) Selected works on synthesis of polymers and pyrolysis of organic raw materials and characterization of obtained products. Toonotprint publisher, Ulaanbaatar, 81-87.

6. A.Ariunaa,B.Q.Li,W.Li,B.Purevsuren,Sh.Munkhjargal, et al. (2007) Coal pyrolysis under synthesis gas, hydrogen and nitrogen. J. Fuel Chem. Tech., 35(1), 1-4.

7. B.Purevsuren, Ya.Davaajav. (2001) Thermal analysis of casein. J. Ther. Anal. \& Calorimet., 65, 147-152.

8. B.Avid, B.Purevsuren et al. (2002) Pyrolysis and TG analysis of the Shivee Ovoo coal Mongolia. J. Ther. Anal. \& Calorimet., 68, 877-885.

9. B.Purevsuren, Ya.Davaajav, S.Batbilig, F.Karaca, J.Namkhainorov, et al. (2013) Characterization of tars from the thermal processing of Baganuur and Tavantolgoi coals from Mongolia, using SEC, UV-F, IR and mass spectrometry. J. Advan. Chem. Eng. Sci., 3(2), 130-144.

10. B.Avid, B.Purevsuren, N.Paterson, Y.Zhuo, D.Peralta, et al. (2004) An exploratory investigation on the perfomence of Shivee-Ovoo coal and Khoot oil shale from Mongolia. J. Fuel. Chem. Tech., 83, 1105-1111.

11. B.Avid, B.Purevsuren. (2001) Chemical composition of organic matter of the Mongolian Khoot oil shale. Oil shale., 18(1), 18-23.

12. B.Avid, M.Born, B.Purevsuren, N.Undrakh, A.Tuvshinjargal. (2003) Thermal behavior of the Khoot oil shale in the different conditions. Oil shale., 20(1), 47-55.

13. Sh.Munkhjargal, B.Purevsuren. (1998) Products of pyrolysis of wood wastes. Reports of the Institute of Chemistry, MAS, 25-28

14. D.Otgonchuluun, B.Purevsuren, A.Ariunaa. (2014) Investigation on pyrolysis and characterization of solid and liquid products after pyrolysis of wood waste. Reports of the Mongolian University of Science and Technology, 2, 68-171.

15. B.Purevsuren, D.Otgonchuluun, A.Ariunaa. (2015) Pyrolysis of wood waste and characterization of obtained products. Reports of the Mongolian Chemical Society, 10, 21-30.

16. B.Purevsuren, B.Avid, T.Gerelmaa, Ya.Davaajav, T.J.Morgan, et al. (2004) The characterization of tar from pyrolysis of animal bones. J. Fuel Chem. Tech., 83, 799-805.

17. S.Batbileg, B.Purevsuren, Ya.Davaajav, J.Narangerel. (2015) Investigation on chemical composition of tar from cedar shell. Scientific Reports of Institute of Chemistry and Chemical Technology., 2, 92-97. (in Mongolian)

18. B.Purevsuren, Ya.Davaajav, F.Karaca, T.J.Morgan, A.George, et al. (2009) Pyrolysis of waste polypropylene and characterization of the tar. Europ. J. Mass Spectro., 15(1), 23-33.

19. B.Purevsuren, Ya.Davaajav. (2001) Investigation on pyrolysis ofcasein. J. Ther.Anal. Calorimet.,66, 743-748.

20. B.Purevsuren, B.Avid, B.Tesche, Ya.Davaajav. (2003) 
A biochar from casein and its properties. J. Mater.Sci., 38(11), 2347-2351.

21. B.Purevsuren, B.Avid, Ya.Davaajav, A.Herod, R.Kandiyoti, et al. (2004) Estimation of the molecular mass range of the tar from pyrolysis of casein by gas chromatography-mass spectrometry, probe mass spectrometry and size-exclusion chromatography with 1-methyl-2-pyrrolidinone as eluent. Europ. J. Mass Spectro., 10, 101-108.
22. B.Purevsuren, Ya.Davaajav, V.Genadiev, H.Kotsev, I.Glavchev. (2013) Investigation of the liquid tar product from pyrolysis of yak-milk casein and its application in curring of epoxy resin. Bulgarian Chemical Communications, 45(2) 157-160.

23. B.Purevsuren, Ya.Davaajav, D.Batkhishig. (2015) Pyrolysis of casein and characterization of obtained solid and liquid products. Mongolian Journal of Chemistry, 16(42), 5-12. 